\title{
Loperamide abuse
}

\author{
Tony Antoniou PhD, David N. Juurlink MD PhD
}

Cite as: CMAJ 2017 June 12;189:E803. doi: 10.1503/cmaj.161421

\section{1} Loperamide is not just an innocuous antidiarrheal agent

At therapeutic doses (16 mg or less per day), loperamide is an opioid with psychoactive effects that are limited by poor absorption when taken orally and active efflux from the central nervous system by the membrane transporter P-glycoprotein. ${ }^{1,2}$ Recreational use of loperamide for its euphoric properities or to lessen symptoms of opioid withdrawal involves large oral dosages (more than $70 \mathrm{mg}$ per day) with or without intentional ingestion of P-glycoprotein inhibitors such as quinine. ${ }^{1}$ Because of its opioid effects, nonprescription status and low cost, loperamide is sometimes referred to as "poor man's methadone."

\section{Abuse of loperamide is increasing}

Of 179 cases of loperamide abuse reported to the United States National Poison Data System between 2008 and 2016, about half were reported after 2014; 137 (77\%) involved men and the median age was 26 years. ${ }^{3}$

\section{3}

Patients may present with cardiac manifestations without overt opioid toxicity

In addition to possible depression of respiratory and central nervous systems, supratherapeutic concentrations of loperamide have been associated with QTC prolongation, QRS widening, ventricular dysrhythmias, syncope and sudden death. ${ }^{3-5}$

4 Diagnosis of loperamide abuse requires a high index of suspicion Loperamide is not detected by routine drug screens. Typically, a patient with loperamide abuse will have a history of opioid misuse or recent discontinuation of prescription opioids and will present with unexplained syncope and electrocardiogram abnormalities.$^{1,4,5}$

\section{Treatment is mostly supportive}

Supportive care is the mainstay of treatment. ${ }^{4}$ Naloxone has been used to reverse coma and respiratory depression. ${ }^{4}$ Optimal management of cardiac toxicity is unknown. Torsades de pointes should be treated with standard therapy, including magnesium and overdrive pacing. ${ }^{4,5}$ Sodium bicarbonate has been used for loperamide-related QRS widening, but its utility is unclear. ${ }^{4,5}$

\section{References}

1. Stanciu CN, Gnanasegaram SA. Loperamide, the "poor man's methadone": brief review. J Psychoactive Drugs 2017;49:18-21.

2. Sadeque AJ, Wandel $\mathrm{C}, \mathrm{He} \mathrm{H}$, et al. Increased drug delivery to the brain by P-glycoprotein inhibition. Clin Pharmacol Ther 2000; 68:231-7.

3. Eggleston W, Marraffa JM, Stork CM, et al. Notes from the field: cardiac dysrhythmias after loperamide abuse - New York, 2008-2016. MMWR Morb Mortal Wkly Rep 2016;65:1276-7.

4. Eggleston W, Clark KH, Marraffa JM. Loperamide abuse associated with cardiac dysrhythmia and death. Ann Emerg Med 2017; 69:83-6.

5. Marraffa JM, Holland MG, Sullivan RW, et al. Cardiac conduction disturbance after loperamide abuse. Clin Toxicol (Phila) 2014; 52:952-7.

Competing interests: None declared.

This article has been peer reviewed.

Affiliations: Department of Family and Community Medicine, St. Michael's Hospital, and Department of Family and Community Medicine, University of Toronto (Antoniou); Institute for Clinical Evaluative Sciences, and Department of Medicine, Sunnybrook Health Sciences Centre (Juurlink), Toronto, Ont.

Correspondence to: Tony Antoniou, tantoniou@ smh.ca 